\section{P016 VASCULAR INVOLVEMENT IN RHEUMATIC DISEASES - THE ROLE OF IMAGING AND IMMUNOLOGICAL BIOMARKERS}

${ }^{1} \mathrm{KM}$ Fischer*, ${ }^{2} \mathrm{H}$ Przepiera-Będzak, ${ }^{1} \mathrm{I}$ Brzosko, ${ }^{3} \mathrm{M}$ Sawicki, ${ }^{2} \mathrm{M}$ Brzosko. ${ }^{1} / \mathrm{ndependent}$ Laboratory for Rheumatologic Diagnostics; ${ }^{2}$ Department of Rheumatology, Internal Medicine and Geriatrics; ${ }^{3}$ Department of Imaging Diagnostics and Interventional Radiology, Pomeranian Medical University in Szczecin, Szczecin, Poland

\subsection{6/annrheumdis-2018-EWRR2019.11}

Career situation of first and presenting author Assistant.

Introduction Vascular abnormalities are common complications in rheumatic patients. Their background is multifactorial and still is a subject of the debate.

Objectives This study was designed to evaluate the significance of selected noninvasive imaging indices, immunological and genetic biomarkers in diagnosis of vascular lesions in rheumatic diseases.

Methods The study group included 288 patients with systemic connective tissue diseases (SCTD).

The noninvasive evaluation of vascular lesions was made on the basis of carotid intima-media thickness (cIMT), ankle brachial index (ABI), high resistance index (HRI) and ulnar artery intraluminal diameter (UAID) measurements using HDI 3500 (ATL).

We analyzed more than 100 variables: autoantibodies, inflammatory and angiogenic markers, genetic polymorphisms and classical risk factors for atherosclerosis.

Statistical analysis was performed with STATA 11 including: chi ${ }^{2}$ Yates, chi ${ }^{2}$ Pearson and rank Spearman correlations tests, logistic regression analysis and multivariate stepwise analysis.

Results Macroangiopathy was influenced by selected autoantibodies including antiphospholipid ( $\mathrm{OR}=4.4 ; 95 \% \mathrm{CI}: 1.1-20.7)$ and anti-endothelial cell $(\mathrm{OR}=6.6 ; 95 \% \mathrm{CI}: 1.6-28.3)$ as well as inflammatory biomarkers $(\mathrm{OR}=3.6 ; 95 \% \mathrm{CI}: 1.1-11.8)$. The analysis of genetic polymorphisms showed especially an important impact of VEGF 2578 AA genotype on atherosclerosis development $(\mathrm{OR}=4.8 ; 95 \% \mathrm{CI}: 1.1-21.1)$. Angiogenic biomarkers were strongly associated with prothrombotic risk $(\mathrm{OR}=22.8$; 95\% CI:2.3-230.6). The analysis of relations between imaging indices and vascular manifestations revealed significant association of cIMT with cardiovascular $(\mathrm{OR}=52.9$; 95\% CI:7.0-1012.7) and cerebrovascular disease $(\mathrm{OR}=4.0$; 95\% CI:1.0-15.3). There was significant reverse correlation between $\mathrm{ABI}$ and peripheral vascular disease $(\mathrm{R}=-0.33$; $\mathrm{p}=0.001)$. HRI values significantly correlated with thromboembolic disorders $(\mathrm{R}=-0.29 ; \mathrm{p}=0.03)$. Finaly, UAID was notably related to microangiopathic complications $(\mathrm{p}<0.05)$.

Conclusions The protocol for vascular lesions diagnosis in SCTD should be based on the combination of imaging and laboratory biomarkers. Immunological and inflammatory factors are crucial in diagnostics of vascular involvement in rheumatic diseases. IMT and ABI showed a high prognostic value and can be used for the general cardiovascular risk stratification.

Disclosure of Interest None declared.

\section{P017 NON-ANTIBODY MEDIATED PATHOGENIC ROLES FOR SYNOVIAL B CELLS IN ACPA+ AND ACPA- RHEUMATOID ARTHRITIS}

${ }^{1}$ A Floudas ${ }^{*},{ }^{2} \mathrm{C}$ Low, ${ }^{1} \mathrm{M}$ Biniecka, ${ }^{2} \mathrm{DJ}$ Veale, ${ }^{1} \mathrm{U}$ Fearon. ${ }^{1}$ Trinity College Dublin; ${ }^{2} \mathrm{St}$. Vincent's Hospital, Dublin, Ireland

10.1136/annrheumdis-2018-EWRR2019.12
Career situation of first and presenting author Post-doctoral fellow. Introduction RF and ACPA have been used extensively for the diagnosis of RA, however no clear mechanism of action towards disease pathogenesis and progression has been identified. Importantly, both seropositive and seronegative RA patients experience significant improvement in disease severity following B cell depletion. Therefore, we hypothesized that B cells have a central role in $\mathrm{ACPA}^{+}$and $\mathrm{ACPA}^{-} \mathrm{RA}$ irrespective of their capacity to produce auto-antibodies.

Objectives To characterize $\mathrm{B}$ and $\mathrm{T}$ cell populations, their recruitment to the inflamed joint, B cell cytokine production and $\mathrm{CD}^{+} \mathrm{T}$ cell polarization in RA synovial tissue biopsies and peripheral blood of $\mathrm{ACPA}^{+}, \mathrm{ACPA}^{-} \mathrm{RA}$ and arthralgia subjects. Methods Synovial tissue biopsies from $\mathrm{ACPA}^{+}$and $\mathrm{ACPA}^{-} \mathrm{RA}$ and $\mathrm{ACPA}^{+}$arthralgia subjects, with paired blood/synovial fluid, were obtained through key-hole arthroscopy and were enzymatically digested. B cell invasion assays and B and CD4 ${ }^{+}$ $\mathrm{T}$ cell in vitro stimulation were conducted under hypoxic conditions simulating the unique environment of the inflamed joint. Flow cytometric analysis was performed.

Results Significant accumulation, compared to peripheral blood, of pro-inflammatory B cells and pro-inflammatory cytokine-producing $\mathrm{CD}^{+} \mathrm{T}$ cells in the synovial tissue and fluid of RA patients, irrespective of ACPA status, as well as the synovial tissue of arthralgia subjects. SPICE analysis of peripheral blood B cells, for a panel of chemokine receptors, revealed a disease-specific expression pattern detected in RA and arthralgia subjects. Importantly, the tissue-invading B cells expressed CXCR3, with in vitro blockade of CXCR3 resulting in reduced $\mathrm{B}$ cell invasion in response to RA synovial tissue biopsy-conditioned media. Under the unique hypoxic conditions of the inflamed joint, RA patient but not healthy subject-derived $\mathrm{B}$ cells produce several pro-inflammatory cytokines including TNF-a and IL- 6 and are capable of polarizing CD4 ${ }^{+}$ $\mathrm{T}$ cells towards a pro-inflammatory phenotype.

Conclusions Accumulation of pro-inflammatory B cell subpopulations in the synovium of both $\mathrm{ACPA}^{+}$and $\mathrm{ACPA}^{-} \mathrm{RA}$ patients underlines a common, antibody-independent, contribution of B cells in synovial inflammation. Arthralgia early in disease, specific chemokine receptor expression and the accumulation of $\mathrm{CXCR}^{+} \mathrm{B}$ cells in the inflamed joint offers an opportunity for therapeutic intervention. Once in the hypoxic environment of the inflamed RA joint, B cells show altered activation, cytokine production and $\mathrm{T}$ cell polarization capacity that could prove important for understanding the role of $\mathrm{B}$ cells in disease pathogenesis of RA.

Disclosure of Interest None declared.

\section{P018 ANTI-CARBAMYLATED PROTEIN ANTIBODIES AS A CLINICAL RESPONSE PREDICTOR IN RHEUMATOID ARTHRITIS PATIENTS TREATED WITH ABATACEPT}

${ }^{1} \mathrm{M}$ Fredi ${ }^{*},{ }^{2} \mathrm{M}$ Boldini, ${ }^{2} \mathrm{R}$ Kumar, ${ }^{1} \mathrm{~S}$ Piantoni, ${ }^{2}$ Cavazzana, ${ }^{3} \mathrm{E}$ Garrafa, ${ }^{2} \mathrm{C}$ Bazzani, ${ }^{1} \mathrm{~A}$ Tincani, ${ }^{1} \mathrm{~F}$ Franceschini. ${ }^{1}$ Rheumatology Unit and Department of Clinical and Experimental Sciences, Spedali Civili and University of Brescia; ${ }^{2}$ Rheumatology Unit, Spedali Civili of Brescia; ${ }^{3}$ Department of Molecular and Translational Medicine, University of Brescia, Brescia, Italy

\subsection{6/annrheumdis-2018-EWRR2019.13}

Career situation of first and presenting author Student for a master or a $\mathrm{PhD}$.

Introduction The presence of anti-carbamylated protein antibodies (anti-CarP) has been detected in rheumatoid arthritis 